\title{
探研绿色建筑材料在土木工程施工中的应用
}

\author{
曹 璞
}

河北建设集团股份有限公司，河北 保定 071000

[摘要] 随着时代的进步和科学技术的发展, 人们对于绿色理念的追求也逐渐的提升。绿色建筑材料以其自身的保温、健康、 环保、安全、隔热等优势为土木工程施工带来了诸多的方便。然而，土木工程要想在快速进步的时代中可持续的发展，就必 须加强和开发绿色的建筑材料。阐述了绿色建材在土木工程中应用的越要性，根据建筑材料的性能. 对其进行了分类，并总 结了绿色建材在土木工程中的应用，希望可以对绿色建材的发展与应用起到促进作用。

[关键词]绿色建筑材料; 土木工程; 施工; 应用探讨

DOI: $10.33142 /$ ec.v2i9.681

中图分类号: TU241

文献标识码：A

\section{Application of Green Building Materials in Civil Engineering Construction} $\mathrm{CAO} \mathrm{Pu}$

Hebei Construction Group Corporation Limited, Hebei Baoding, 071000 China

\begin{abstract}
With the progress of the times and the development of science and technology, people's pursuit of green concept has been gradually promoted. Green building materials bring a lot of convenience to civil engineering construction because of their own advantages of heat preservation, health, environmental protection, safety, heat insulation and so on. However, if civil engineering wants to develop sustainably in the era of rapid progress, it is necessary to strengthen and develop green building materials. This paper expounds the more important the application of green building materials in civil engineering, classifies them according to the properties of building materials, and sums up the application of green building materials in civil engineering. It is hoped that the application of green building materials can promote the development and application of green building materials. .
\end{abstract}

Keywords: Green building materials; Civil engineering; Construction; Application discussion

\section{引言}

就以往陈旧形式的土木工程施工工序来说, 施工人员通常所使用的都是传统型的施工物料。但是在社会快速发展 的带动下, 使得民众的思想意识得到了显著的进步, 进而越发的重视环境保护工作。与传统型施工物料相对比来看, 绿色环保物料具备良好的环境保护效果, 不会对人体健康造成任何的损害, 就成本方面来看, 绿色施工物料与传统施 工物料相比较, 在环境保护效果以及经济方面具有更强的友乐心。整体上来看, 在当前的社会发展趋势中, 在土木工 程建筑中，切实的运用环保物料，不但能够达到良好的环境保护效果，并且能够有效地促进人类与环境和谐发展。

\section{1 绿色建筑材料在土木工程实施中的必要性}

\section{1 实现土木工程建筑的可持续发展}

资源节约型和环境友好型社会的创建都是需要绿色环保物料的切实运用的辅助的。就现如今的土木工程施工来说, 建筑施工物料如果不能打破传统思想的束缚, 切实的大范围的将环保物料加以运用, 不但会增加工程整体成本, 并且 会在施工中形成诸多的污染物质，会对环境造成诸多的损坏，并且对于人类的身体健康也是非常不利的。如果能够充 分的结合实际，来将环保物料加以全面的运用，不但能够提升整个工程的节能效果，并且可以有效的达到资源节省和 环境保护的目的, 更好的避免工程施工工作导致的环境损坏问题。鉴于此, 在土木工程建筑中大范围的利用绿色建筑 物料，不单纯是工程环保性能的现实呈现，并且也是社会发展的必然趋势。

\section{2 有利于实现国家经济的转型}

专业人士都知道, 国家的经济基础与国民经济的进步都是与建筑行业存在密切的关联的。进而, 建筑行业的发展 情况也与国家的经济基础存在密切的关联。换句话说, 社会经济的快速发展有效的促进了建筑行业的健康发展。在现 如今的土木工程现实情况来说, 土木工程在实际建造中选择使用的绿色环保物料作用可以说是较为关键的, 绿色施工 物料的切实运用能够有效的提升资源的利用效率，进而能够达到国家经济资源高效利用的目标。进而大范围的在土木 工程施工中引用绿色物料，可以说对于促进国家经济的健康发展会起到积极的影响作用。 


\section{3 提高消费者对绿色建筑材料的需求}

在社会迅猛发展以及民众生活水平大幅度提升的影响下, 民众对于生活环境的需求也在逐渐的提升, 进而对生活 环境以及各类生活用品提出了更高的要求。在社会快速发展的影响下, 使得民众的思想发生了明显的变化, 并且人们 对于环境保护, 绿色施工, 节能减排等新的概念都有了更加准确的认识, 在针对生活环境以及日用品的选择来说, 越 发的重视绿色和环保理念的运用。但是就现如今土木工程建筑中所选择使用的绿色施工物料的情况来说, 大部分都是 结合了消费者的实际消费需要来加以设计的。绿色是消费者越发关注的问题, 很多的民众的消费观念逐渐的提升, 进 而对绿色施工物料的研究力度也在逐渐的提升。进而消费者的消费需求可以说与绿色建筑施工物料的研究和使用存在 一定的关联, 绿色施工物料的研究和广泛的利用从某种层面上来说促进了消费者对绿色施工物料的需求的提升 ${ }^{[1]}$ 。

\section{2 绿色建筑材料的分类}

绿色建筑材料结合其性质可以花费为四种类型, 即可循环利用型、节能型、环保型、安全型。其中可循环型物料 其实质就是说那些些施工物料能够加以重复利用或者也可以在二次回收之后进行加工处理之后可以被二次利用, 这样 不但能够提升资源的利用效率, 并且可以有效的避免出现资源浪费的情况。环保型物料其实质就是那些在工程施工中 加以使用之后不会对使用者的身体造成损害, 并且不会对周边环境造成破坏的施工物料。安全型物料其实质就是在被 运用到工程建筑之中的时候, 不会造成任何的不良后果出现, 工程结构安全性较强。结合施工物料的性能, 可以将其 划分为三个类型, 即功能性材料、结构性材料以及装饰性材料。与其他类型的施工物料相对比来说, 功能性施工物料 酒气外部结构形式来说相对较为复杂, 但是其性能会在工程建造完成之后才能凸显出来。结构性物料主要涉及到环保 水泥, 防水物料以及轻便型施工物料等等 ${ }^{[2]}$ 。

\section{3 土木工程施工中应用绿色建筑材料应注意的问题}

\section{1 就选材而言}

在将新型绿色建筑施工物料大范围的加以运用之后, 人们越发的清楚了解到了陈旧的建筑物料无论是在环保性能 方面还是在是工程成本方面都优秀于传统型的施工物料, 这也使得人们对于绿色物料的概念得到了全面的了解。但是 就现如今的建筑行业施工物料实际情况来说, 种类十分繁多, 进而需要我们在正式开始施工之前, 结合实际情况和需 求来对施工物料加以切实的选择。诸如, 在土木工程建筑中不能切实的对新型环保物料加以选用, 势必会在工程建筑 中产生大量的污染物, 势必会对建筑内部或者是外部都会造成严重的不良影响, 甚至会威胁到工程施工人员的人身安 全。但是在施工前期实施物料挑选工作的时候选择使用绿色环保物料, 能够较好的解决灰尘污染的问题, 不管是对人 体健康保护还是对环境保护工作都会起到积极的促进作用。最后不得不说的是, 竹制材料尽管具有良好的安全性, 环 保型, 但是在这一物料的生产中会消耗大量的人力物力, 进而在针对土木工程施工实施选材工序的时候, 务必要充分 的联系工程现实情况来对施工物料加以选择, 确保施工物料的切实性 ${ }^{[3]}$ 。

\section{2 就施工和验收而言}

在土木工程施工中的物料选择工作中, 不但需要重视物料质量的保证, 并且需要施工人员具备丰富的施工经验。 施工的中绿色物料的运用效果与工程施工的质量存在一定的关联, 工程验收效果与绿色建筑施工物料的价值体现存在 一定的关联, 进而在实际的工程建筑中, 需要充分的联系多个层面的因素从整体上进行分析研究, 秉承绿色环保的理 念, 对施工成本, 资金回笼实施切实的预算, 务必要联系实际更好的对绿色环保物料加以引用, 更好的施展出绿色环 保物料的作用。再有, 在实施土木工程建筑工序的时候, 施工单位为了获得更加丰厚的收益, 往往会在工程施工中地 施工物料进行无限的缩减，这样不但会制绿色施工物料作用的发挥，并且还会对施工质量造成严重不良影响。

\section{4 节能绿色环保建筑材料在工程中的应用}

\section{1 隔热保温材料}

在利用传统施工物料进行工程建筑之后, 需要对混凝土结构以及钢筋混凝土结构支撑墙体实施保温处理, 因为以 往陈旧形式的施工物料自身具备非常明显的单一性, 进而无法实现既定的保温的效果, 鉴于此施工单位需要引用绿色 环保节能物料来对上述问题加以解决。现如今, 在实施工程墙体结构建造工作的时候, 通常最为普遍的方法就是在墙 体表层铺设保温物料, 进而有效的控制热能的损失和浪费。对墙体实施的加工处理所采用的方法通常都是粘贴保温物 料，对墙体内层往往会涂抹环保涂料来降低室内环境对正常生活造成的的不良影响 ${ }^{[4]}$ 。 


\section{2 节能环保玻璃}

玻璃结构自身具备较强的透视性能, 并且透光效果较好, 在市场中的种类繁多, 进而各个类型之间的性能差异也 是十分明显的, 在切实加以运用的时候, 可以结合建筑结构的不同性能加以切实的选用。不能一味地追求节省成本而 选择那些质量低下的玻璃物料, 也不可以单纯的追求豪华而选择使用那些高档的玻璃, 需要秉承绿色环保的理念, 更 好的对绿色环保玻璃性能发挥出来。还需要秉承节能环保的原则, 来大范围的对节能环保玻璃物料加以大范围的运用, 更好的提升室内空间的照明效果, 提升室内的舒适度 ${ }^{\left[{ }^{[3]}\right.}$ 。

\section{3 墙体环保材料}

在陈旧形式的混凝土结构建造完成之后，会对混凝土结构利用烧结砖来实施填充，因为成本花费较多，并且会对 环境造成严重的损坏, 鸡儿现如今已经逐渐的开始使用水泥, 沙土来制作成混凝土空心砖来取代烧结砖。空心砖可以 结合工程性质以及填充需要来进行规格的调整。在最近的几年时间里研发出来的新型的轻体施工物料都是由专门的结 构物料建造而成的, 这一物料在建筑墙体, 楼梯结构中的运用较为频繁, 其与传统的混凝土物料相比较, 在保温, 隔 热方面表现的更加优秀 ${ }^{[6]}$ 。

\section{5 环保型建筑节能材料的发展趋势}

结合建筑行业需求, 环保型建筑节能材料有可能会按照以下趋势发展：(1资源节约型材料。据有关数据显示：目 前我国工业废渣、生活垃圾的年产量约在 20 亿吨左右。如果研发出高利用率的节能材料, 就能降低材料消耗, 提升产 品成品率, 从而实现资源节约。(2)能源节约型材料。其主要就是指充分利用可再生能源, 实现节能。如研发出能够充 分利用太阳能的节能材料。(3)空间绿色节能材料，主要是指能够降低有害气体排放的新型材料研发。

\section{6 结束语}

随着绿色建筑材料及其生产水平的成熟，绿色建筑材料的使用和发展已经是必然趋势，但是，此类材料在运用过 程中还需要注意很多地方, 以保证绿色材料的优势得到充分的发挥, 促进建筑行业的发展。另外, 在全球建筑行业未 来的发展道路中, 绿色建筑材料会占据极大的市场份额, 满足人们对绿色环保的要求。

\section{[参考文献]}

[1]殷国庆. 研究土木工程施工中绿色建筑材料的运用 [J].建材与装饰, 2017 (51) : 44-45.

[2]俞雪飞,黄效辉. 基于木工程施工中绿色建筑材料的应用分析 [J]. 江西建材, 2017 (09) : 134.

[3] 管林龙.绿色建筑材料在土木工程施工中的应用 [J].住宅与房地产,2017 (30) : 130 .

[4] 牛小云, 宋巍. 绿色建筑材料在土木工程施工中的应用 [J].住宅与房地产, 2017 (33) : 110 .

[5]郭歌。绿色建筑材料在土木工程施工中的应用探究 [J].企业科技与发展, 2019(05): 171-172.

[6]吴辉.绿色建筑材料在土木工程施工中的应用探讨 [J]. 现代物业 (中旬刊), 2019 (03) : 223 .

作者简介: 曹璞 (1985-) , 毕业学校: 河北建筑工程学院; 现就职于河北建设集团股份有限公司技术负责人。 